This is the final peer-reviewed accepted manuscript of:

Cellini, Roberto, Luca Lambertini, and Gianmarco IP Ottaviano. "Strategic inattention, delegation and endogenous market structure." European Economic Review 121 (2020): 103324.

The final published version is available online at:

https://doi.org/10.1016/i.euroecorev.2019.103324

(C) 2020. This manuscript version is made available under the Creative Commons AttributionNonCommercial-NoDerivs (CC BY-NC-ND) 4.0 International License (http://creativecommons.org/licenses/by-nc-nd/4.0/) 


\title{
Strategic inattention, delegation and endogenous market structure*
}

\author{
Roberto Cellini $^{a}$ Luca Lambertini $^{b}$ and Gianmarco I.P. Ottaviano ${ }^{c}$
}

July 25, 2019

\begin{abstract}
We model an industry in which a discrete number of firms choose the output of their differentiated products, deciding whether or not to consider the impact of their decisions on aggregate output. The firm's choice of ignoring the impact of its production on aggregate output, which is typical of monopolistic competition, is derived as an equilibrium choice rather than assumed upfront. Such a choice is labelled as 'strategic inattention'. We show that our model of 'strategic inattention' is isomorphic to a model of 'strategic delegation' with managerial compensation based on relative profit performance. Thus, monopolistic competition and Cournot oligopoly are reconciled within a general model which can lead to either market form.
\end{abstract}

Keywords: information; strategic interaction; monopolistic competition; oligopoly; delegation.

JEL Codes: D43, L13.

\footnotetext{
*Contacts: ${ }^{a}$ University of Catania, cellini@unict.it; ${ }^{b}$ University of Bologna, luca.lambertini@unibo.it (corresponding author); ${ }^{c}$ Bocconi University, gianmarco.ottaviano@unibocconi.it.

We thank the Editor, Robert Sauer, an Associate Editor, two anonymous referees, Herbert Dawid, Stephen Martin, Martin Peitz, Juan Prieto Rodriguez, Jacques-François Thisse and the audience at several seminars and conferences for useful comments and suggestions on previous drafts. The usual disclaimer applies.
} 


\section{Introduction}

Oligopoly models à la Cournot assume that firms choose their output levels considering the impact of their individual choices on overall industry output. In monopolistic competition models firms are assumed to take, instead, industry output as given. With a continuum of firms this assumption is inconsequential as there is no individual impact on the industry. Differently, with a discrete number of firms each firm does have an individual impact on the industry, but monopolistic competition models make the behavioral assumption that the firm neglects this piece of information.

A common way to justify this neglect is to argue that, for some purposes, monopolistic competition provides a convenient approximation of the Cournot equilibrium when there is a 'large number' of firms so that the individual impact of any of them on the industry can be considered negligible in practice (Dixit and Stiglitz, 1977). This justification has been criticized as being both mathematically inconsistent (Keen and Standish, 2006) and not necessarily innocuous in terms of approximating the correct market outcome (d'Aspremont et al., 1996). We provide a justification of why a discrete number of firms may disregard the impact of their individual choices on aggregate output: there might well be circumstances in which a firm's profit maximizing choice is indeed to strategically neglect that piece of information so that an industry equilibrium emerges in which a discrete number of firms choose to behave as monopolistic competitors rather than as oligopolists.

Our model considers an industry in which a discrete number of firms supply horizontally differentiated products. Demand is linear in quantity consumed and total cost is quadratic in the quantity produced. Firms are single-product profit-maximizers and play a non-cooperative two-stage game. In the first stage, they simultaneously decide whether or not to use information that industry output equals the sum of their individual outputs. In the second stage, they choose their output levels based on information that in the first stage they decided to use. If they decide to consider their individual impact on industry output, in the second stage market structure corresponds to a familiar Cournot oligopoly. If they choose instead to neglect that impact, in the second stage market structure corresponds to monopolistic competition. Note that the first stage choice corresponds to a decision on whether or not strategically ignore a piece of available information.

We show that either or both alternative market structures may emerge in equilibrium, depending on the values of demand and cost parameters, and on 
the number of firms. For a given number of firms, high (low) product differentiation and weak (strong) negative reaction of marginal cost to scale give rise to a unique subgame perfect equilibrium in pure strategies characterized by oligopoly (monopolistic competition). Oligopolistic and monopolistically competitive subgame perfect equilibria in pure strategies coexist, instead, for intermediate product differentiation and moderate reaction of marginal cost to scale. For given demand and cost parameters, oligopoly (monopolistic competition) arises in the subgame perfect equilibrium in pure strategies when the number of firms is low (large) while an oligopolistic and a monopolistically competitive subgame perfect equilibria in pure strategies coexist for an intermediate number of firms. The outcome in which some firms behave as oligopolists and others as monopolistic competitors never arises in a subgame perfect equilibrium in pure strategies. However, such a mixed outcome can be interpreted as the empirical counterpart of the subgame perfect equilibrium in mixed strategies.

Thus, our model shows that, for a wide range of parameter values, monopolistic competition is not just an approximation of the exact oligopolistic equilibrium, but it is 'the' equilibrium market structure, provided that firms can decide to strategically neglect the aggregate impact of their choices. We also show that, rather than being a mere intellectual curiosity, a firm's strategic neglect of its individual impact on the industry is implied by a simple realistic managerial contract based on Relative Performance Evaluation (RPE), in which firms benchmark their managers' performance in terms of own profit against rivals' average profit, as in Aggarwal and Samwick (1999).

Our analysis contributes to four strands of literature. First, a key feature of our model is that the market regime (oligopoly or monopolistic competition) is determined endogenously by the strategic choices of firms. In this respect, our analysis is related to the literature on the endogenous determination of market structure through the entry process (Etro, 2008, 2011; Dunne et al., 2013). The focus on entry and exit is also the hallmark of old and new models of monopolistic competition (Spence, 1976; Dixit and Stiglitz, 1977; Ottaviano et al., 2002; Behrens and Murata, 2007). Our analysis takes the reverse angle, studying how oligopoly or monopolistic competition endogenously arise in equilibrium for a given industry structure. ${ }^{1}$ Moreover, our approach can be connected to common agency games, from Bernheim and

\footnotetext{
${ }^{1}$ Our model could be easily extended to characterise the entry process and the number, nature and size of active firms at the long-run equilibrium.
} 
Whinston (1985, 1986) to d'Aspremont and Dos Santos Ferreira (2010). In particular, the latter contribution shows that any outcome ranging from perfect competition to collusion, including monopolistic competition, can emerge as an equilibrium outcome when firms act as principals and the representative consumer behaves as an agent.

Second, in our model information on a firm's individual impact on the aggregate is freely accessible. Still, it can be individually convenient for a firm to ignore that piece of information. In this respect, we contribute to the literature showing that information is not relevant per se, but rather for the way it affects players' best replies to rivals (Kamien et al., 1990; Bassan et al., $1997 ; 2003) .^{2}$

Third, our analysis also speaks to the studies on the interactions among asymmetric firms differing along several dimensions such as size, objectives and organization. Chirco et al. (2013) provide a review of theoretical, empirical, and experimental works supporting the coexistence of heterogeneous motives for firms in an oligopolistic market, with specific attention to strategic delegation to managers. In Kokovin et al. (2014) oligopolistic and monopolistically competitive firms interact in markets with differentiated products. In their model, however, asymmetry is given and linked to exogenous differences in firm size, with large oligopolists interacting with a fringe of small monopolistic competitors (see, also, Shimomura and Thisse, 2012, and Parenti, 2018). In the same vein, Anderson et al. (2013) use the concept of 'aggregative game' to analyze the free entry of firms in markets where oligopolistic and monopolistically competitive producers coexist.

Fourth and last, we contribute to the literature on strategic delegation games. In our model the choice of neglecting information on the aggregate impact of individual output supports more aggressive market behaviour. The

\footnotetext{
${ }^{2}$ Similarly, Kadane et al. (1996) show that a Bayesian agent may find it rational not to pay to acquire information. Safra and Sugarik (1993) make a similar point for cases in which agents do not choose according to the expected utility principle. In Barros (1997), by ignoring information on the actions taken by their sales agents, oligopolistic principals forgo the possibility of appropriating the agents' benefits from their relation specific-investments, which ends up increasing the principals' expected profits. Limited ability to process information has also been used to explain why agents may not fully exploit available information. For example, in rational inattention models available information is not used because the ability to translate information into action is assumed to be constrained by a finite capacity to process information (see, e.g., Sims, 2010, or Wiederholt, 2010, for a survey). In our model information is freely processable, so processing capacity is not an issue and inattention arises, instead, from strategic behavior.
} 
problem faced by firms in our setup closely resembles the strategic choice of delegating market strategies to managers, analyzed in Vickers (1985) and several follow-ups. In this research strand, Vickers (1985), Fershtman and Judd (1987) and Sklivas (1987) consider managerial incentives based on a combination of profits and output or revenues; Jansen et al. (2007) and Ritz (2008) those based on profits and market shares; Salas Fumas (1992), Aggarwal and Samwick (1999) and Miller and Pazgal (2001) examine contracts based on comparative performance. ${ }^{3}$ This entails that the latter class of contracts explicitly accounts for rivals' profits in shaping a manager's remuneration. We show that the conditions that dictate the emergence of oligopoly or monopolistic competition as equilibrium market structures in our game are isomorphic to the ones that support strategic delegation to managers through a simple contract based upon comparative performance evaluation. ${ }^{4}$

The rest of the paper is organized as follows. The layout of the model is in section 2, while sections 3 and 4 respectively present the Cournot-Nash and the monopolistically competitive equilibria. The isomorphism between monopolistic competition (or inattention) and strategic delegation via contracts based on Relative Performance Evaluation is illustrated in section 5 . The endogenous choice of firms about whether to be attentive or not is the topic of section 6 . Concluding remarks are in section 7 .

\section{The Market model}

Consider an industry in which $n$ single-product firms (indexed by $h=1, \ldots, n$ ) sell $n$ horizontally differentiated products facing linear inverse demand

$$
p_{h}=a-\beta q_{h}-\sigma Q,
$$

\footnotetext{
${ }^{3}$ Moreover, Jansen et al. (2009; see also Lambertini, 2017, ch. 2) prove that, in the Cournot model, delegation based on comparative performance emerges at the subgame perfect equilibrium of a multistage game in which owners choose whether to delegate control to managers or not and through which specific incentive (output/revenues, market shares, comparative performance).

${ }^{4}$ Empirical evidence on the widespread adoption of managerial contracts based on comparative performance can be found in Barro and Barro (1990), Janakiraman et al. (1992), Joh (1999), Gibbons and Murphy (1990) and Murphy (1999).
} 
where $a, \beta$ and $\sigma$ are positive parameters, $p_{h}$ and $q_{h}$ are the price and the output level of firm $h$, while $Q=\sum_{h=1}^{n} q_{h}$ is industry output. ${ }^{5}$ Total cost is assumed to be a quadratic function of output:

$$
c_{h}=c q_{h}+b q_{h}^{2}
$$

While the demand parameters are assumed to be positive, the cost parameters are assumed to be non-negative with $c<a .^{6}$ To make future expressions less cumbersome, it is useful to define the following positive bundling parameters

$$
\alpha \equiv \frac{a-c}{\beta+b}, \eta \equiv \frac{\sigma}{\beta+b}, \gamma \equiv \beta+b
$$

so that the profit of firm $i$ can be written as

$$
\pi_{h}=\gamma\left(\alpha-q_{h}-\eta Q\right) q_{h}
$$

where all parameters are again positive. Among them, as we will see, the key parameter will turn out to be $\eta$. This measures the impact of aggregate output $Q$ on the firm's profit margin $\pi_{h} / q_{h}$ relative to the impact of own output $q_{h}$. Equivalently, it measures the (absolute value of the) change in $q_{h}$ needed to keep the profit margin unchanged for a given change in $Q$. Intuitively, $\eta$ measures the dependence of the firm's profit on the industry aggregate. In the limit case $\eta=0$ the firm's profit is independent from aggregate output. As $\eta$ grows, the firm's profit increasingly depend on aggregate output. Hence, we call $\eta$ the 'aggregate dependence' parameter. In the case of constant marginal cost $(b=0), \eta$ is a pure demand parameter inversely measuring the extent of product differentiation: stronger product differentiation implies lower aggregate dependence. With increasing marginal cost $(b>0)$, aggregate dependence is also affected by the gradient of marginal cost. The game takes place under complete and symmetric information, with simultaneous moves.

\footnotetext{
${ }^{5}$ In the case of a discrete number of firms, (1) corresponds to the demand function first introduced by Bowley (1924) and then revisited, inter alia, by Spence (1976), Dixit (1979) and Singh and Vives (1984). Tabuchi et al (2002) and Melitz and Ottaviano (2008) have adapted it to the case of a continuum of firms.

${ }^{6} \mathrm{We}$ assume linear demands because this specification yields straightforward comparative statics. In light of Aggarwal and Samwick (1999), the results in this section can be generalized to nonlinear demand functions as long as $\partial p_{h}\left(q_{h}, Q\right) / \partial q_{h}<0$ and $\partial p_{h}\left(q_{h}, Q\right) / \partial Q<0$
} 


\section{The Cournot-Nash equilibrium}

If all firms behave as Cournot oligopolists, (4) rewrites as

$$
\pi_{h}^{C}=\gamma\left(\alpha-q_{h}^{C}-\eta \sum_{i=1}^{n} q_{i}^{C}\right) q_{h}^{C}
$$

where superscript $C$ stands for Cournot. Using the standard procedure one may derive the individual output and profits in Cournot-Nash $(C N)$ equilibrium:

$$
q^{C N}=\frac{\alpha}{2+\eta(n+1)} \text { and } \pi^{C N}=\frac{\alpha^{2} \gamma(1+\eta)}{[2+\eta(n+1)]^{2}}
$$

Individual profits are positive in equilibrium. The next section uses this benchmark to evaluate the properties of alternative settings that involve harsher market competition.

\section{Monopolistic Competition}

Consider first the scenario in which all firms are unaware of their individual impact on aggregate output and therefore on equilibrium price(s). We will refer to the situation of such unawareness as 'strategic inattention'. This portrays monopolistic competition as in Ottaviano et al. (2002) and Melitz and Ottaviano (2008). Taking $Q$ as a parameter, the optimal production level of each firm, and the corresponding profit, are respectively equal to

$$
q^{m}=\frac{\alpha}{2+\eta n} \text { and } \pi^{m}=\frac{\alpha^{2} \gamma}{(2+\eta n)^{2}}
$$

where superscript $m$ stands for monopolistically competitive. These are generated by the first order condition

$$
\frac{\partial \pi_{h}}{\partial q_{h}}=\alpha-2 q_{h}-\eta Q=0
$$

which can be rewritten as

$$
\alpha-2 q_{h}-\eta\left(q_{h}+\sum_{j \neq h} q_{j}\right)=0
$$


and then solved imposing symmetry on outputs. Relying on (9), one can also draw the best reply of firm $h$ against any of its rivals, and compare the resulting map of reaction functions with that associated to Cournot behavior.

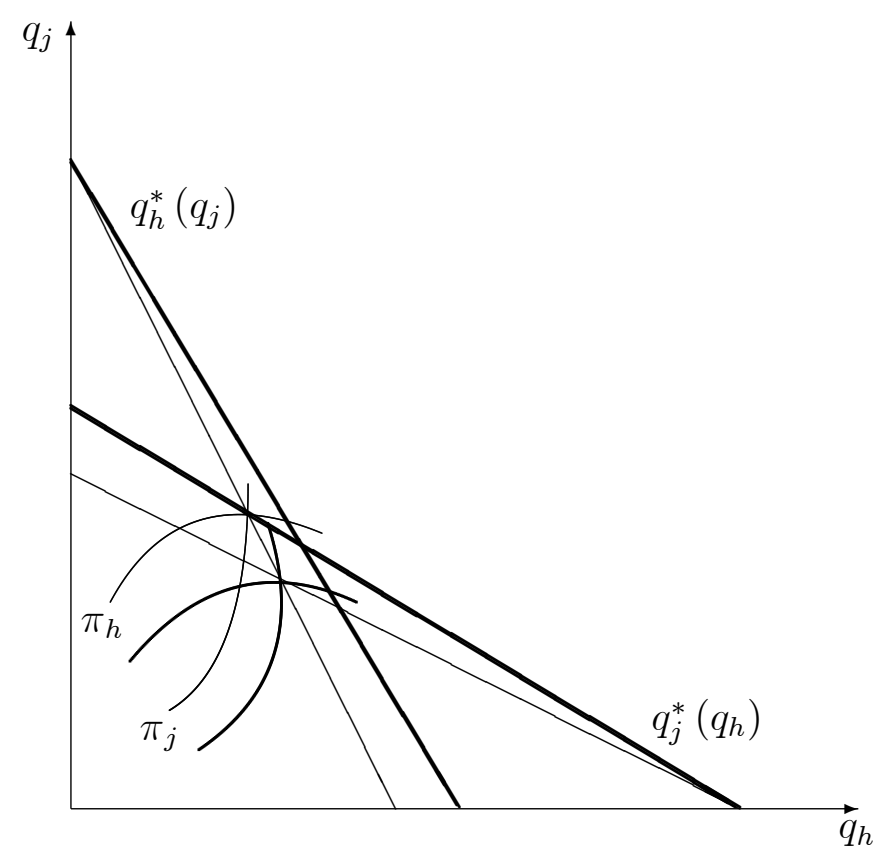

Figure 1 Best replies: Cournot vs monopolistic competition

This is what appears in Figure 1, in which $q_{h}$ and $q_{j}$ are measured along the horizontal and vertical axes, respectively. The graph portrays the best replies of any two firms out of the $n$ operating in the industry. The two thin lines correspond to the case in which firms are oligopolistic; the thick ones to the case in which they are monopolistically competitive. The oligopoly outcome $\left(q_{h}^{C N}=q_{j}^{C N}=q^{C N}\right)$ and the monopolistically competitive outcome $\left(q_{h}^{m}=q_{j}^{m}=q^{m}\right)$ can be found at the crossing of the two thin lines and the two thick lines, respectively. Both crossings are on the 45-degree line passing through the origin (not drawn to avoid cluttering the figure) where firms produce the same level of output. The remaining two crossings involve a thin and a thick lines. They are symmetric around the 45-degree line passing through the origin. The one above this line entails that firm $h$ is a monopolistically competitive unit while firm $j$ behaves as a Cournot oligopolist; the other crossing is its mirror image. In either case, being more aggressive 
against a Cournot player pays off, as implied by the thin isoprofit curves.

Our Figure 1 looks the same as Figure 2 in Aggarwal and Samwick (1999, p. 2012), which compares the best replies under standard differentiated Cournot duopoly with the best replies when firms' owners delegate output choices to managers through compensation based on a linear combination of own and rival's profits. This suggests the possible existence of a fundamental isomorphism between our model of strategic inattention and their models of strategic delegation. The aim of the following section is to nail down such isomorphism.

\section{Strategic inattention as strategic delega- tion}

Consider the following delegation model: $n$ quantity-setting firms offer differentiated products in a two-stage game, each one taking place under complete, symmetric and imperfect information. In the first stage, owners delegate control to managers. In the second, managers choose output levels.

Delegation is implemented through a simple and realistic Relative Performance Evaluation (RPE) contract in which the manager of a firm is rewarded (penalized) for profit above (below) industry average. This assumes that the manager's action at the second stage is not contractible, whereas profits are contractible. Indeed, this reflects the idea that managers' strategies may not be observable by owners, while profits are; that is, even if this class of models assumes complete information, a pinch of realism drives the assumption that owners cannot spell out the details of their agents' behaviour. ${ }^{7}$ Firm $h=1, \ldots, n$ offers its manager compensation $w_{h}=k_{h}+\pi_{h}-\bar{\pi}$, where $k_{h}$ is set by the owner to drive the manager's remuneration to reservation wage $\widehat{w}$ determined on a competitive labour market, and $\bar{\pi} \equiv\left(\sum_{z=1}^{n} \pi_{z}\right) / n$ is average industry profit. ${ }^{8}$

\footnotetext{
${ }^{7}$ The assumption that managers' decisions are not contractible could be justified by introducing a common additive shock affecting firms' profits as in Aggarwal and Samwick (1999). The shock would make it impossible to perfectly infer the managers' actions from profits. We prefer to leave this justification implicit in order to streamline the presentation.

${ }^{8}$ This simple contract would not be the optimal contract if firm owners were allowed to choose the weights attached to own and average industry profits in the manager's compensation. In this case, as shown by Salas Fumas (1992), Aggarwal and Samwick (1999) and Miller and Pazgal (2001) in duopoly models, the optimal weights would depend
} 
All firms are attentive, whereby all of them know that $Q=\sum_{\ell=1}^{n} q_{\ell}$. If owners do not delegate, the second stage delivers the standard Cournot outcome (6), as in Section 2. If instead owners hire managers, in the second stage each of the latter chooses $q_{h}$ to maximize $w_{h}$, i.e.,

$$
w_{h}=k_{h}+\gamma\left[\left(\alpha-q_{h}-\eta \sum_{\ell=1}^{n} q_{\ell}\right) q_{h}-\frac{\sum_{z=1}^{n}\left(\alpha-q_{z}-\eta \sum_{\ell=1}^{n} q_{\ell}\right) q_{z}}{n}\right]
$$

so that the FOC

$$
\frac{\partial w_{h}}{\partial q_{h}}=\gamma\left(\frac{\partial \pi_{h}}{\partial q_{h}}-\frac{\partial \bar{\pi}}{\partial q_{h}}\right)=\gamma\left(\frac{\partial \pi_{h}}{\partial q_{h}}+\frac{\eta \sum_{z=1}^{n} q_{z}}{n}\right)=0
$$

Imposing symmetry $Q=n q,(11)$ can be solved to yield output and profit under industry-wide delegation:

$$
q^{d}=\frac{\alpha}{2+\eta n} \text { and } \pi^{d}=\frac{\alpha^{2} \gamma}{(n \eta+2)^{2}}
$$

in which superscript $d$ mnemonics for delegation.

Comparing (12) with (7) reveals that strategic delegation under the simplest profit-based RPE contract leads to the same outcome as monopolistic competition where every individual firm neglects the impact of its own output choice on aggregate production. That is, an observer looking at the outcome of the game described in this section would be unable to infer whether it has been produced by a managerial firm or by a monopolistically competitive firm.

As we know from Fershtman et al. (1991), any type of strategic delegation contract must be public domain in order to be effective. This amounts to saying that any firm must correctly identify the position of the rivals' best replies. Consequently, the equivalence between delegation based on RPE and a monopolistically competitive stance implies that both groups of firms must know exactly who is attentive or inattentive. This is part of the assumption of complete information.

On the basis of the foregoing discussion, we can state:

on demand parameters. To our purposes, allowing owners to offer the simple RPE contract envisaged here is a useful simplification. 
Proposition 1 Consider an industry in which $n$ firms either behave as monopolistically competitive units or delegate control to managers in charge of setting the output levels through RPE contracts. The outcomes of the symmetric subgames in which all firms either (i) behave as monopolistically competitive agents or (ii) delegate control to managers are isomorphic.

Proposition 1, together with the Cournot equilibrium (7), prompts the question whether all firms in the industry will adopt an identical attitude (or internal organization) or not. This issue is addressed in the next section, in which the choice of the objective function is endogenized by assuming that firms play a two-stage game, with both stages characterized by complete, symmetric and imperfect information, and the decision to be attentive or not is modelled by borrowing a well know tool from coalition theory.

\section{Attention vs inattention}

Consider again the same differentiated industry, populated by $n$ single-product firms. The two-stage game has the following nature. In the second stage, firms $h=1, \ldots, n$ simultaneously maximize profit $\pi_{h}$ with respect to their output level $q_{h}$. In the first stage, they simultaneously decide whether in the second-stage profit maximization they will take the condition $Q=\sum_{i=h}^{n} q_{h}$ into account or rather take $Q$ as given. We look for subgame perfect equilibria in pure strategies focusing on symmetric outcomes. Henceforth, we will refer to inattentive firms as monopolistically competitive whereas attentive ones will be labeled as Cournot firms.

\subsection{Stage II}

Solving backwards, we start with the second stage and consider a generic composition of the industry in which $k$ firms have decided to disregard their own impacts on aggregate production and $n-k$ firms have decided to remain attentive. Industry output can then be expressed as

$$
Q=\sum_{i=1}^{k} q_{i}^{m}+\sum_{j=k+1}^{n} q_{j}^{C}
$$

where $q_{i}^{m}$ is the output of the generic monopolistically competitive firm $i$, with $i=1, \ldots, k$, and $q_{j}^{C}$ is the output of the generic Cournot firm $j$, with $j=k+1, \ldots, n$. 
Given (4), the FOC for profit maximization by a Cournot firm can be written as

$$
\frac{\partial \pi_{j}^{C}}{\partial q_{j}^{C}}=\gamma\left[\alpha-(2+\eta) q_{j}^{C}-\eta Q\right]=0,
$$

with the second order condition (SOC) being satisfied for all parameter values. After imposing symmetry $q_{i}^{m}=q^{m}$ for all $i=1, \ldots, k$ and $q_{j}^{C}=q^{C}$ for all $j=k+1, \ldots, n,(13)$ becomes $Q=k q^{m}+(n-k) q^{C}$ and thus (14) can be rewritten as

$$
\alpha-[2+\eta(n-k+1)] q^{C}-\eta k q^{m}=0 .
$$

Analogously, the FOC of a monopolistically competitive firm is

$$
\frac{\partial \pi_{i}^{m}}{\partial q_{i}^{m}}=\gamma\left(\alpha-2 q_{i}^{m}-\eta Q\right)=0
$$

Again, the SOC is satisfied for all parameter values. Using (13) with symmetry, (16) can be rewritten as

$$
\alpha-(2+\eta k) q^{m}-\eta(n-k) q^{C}=0 .
$$

Conditions (15) and (17) together imply that the equilibrium output levels are:

$$
q^{C}(k, n)=\frac{2 \alpha}{4+2 \eta(n+1)+\eta^{2} k}
$$

and

$$
q^{m}(k, n)=\frac{(2+\eta) \alpha}{4+2 \eta(n+1)+\eta^{2} k}
$$

respectively, with equilibrium industry output

$$
Q(k, n)=\frac{(2 n+\eta k) \alpha}{4+2 \eta(n+1)+\eta^{2} k} .
$$

The output levels in (18-20) exhibit the following properties:

$$
\frac{\partial Q(k, n)}{\partial n}>0 ; \frac{\partial Q(k, n)}{\partial k}>0 ; \frac{\partial q^{\ell}(k, n)}{\partial n}<0 ; \frac{\partial q^{\ell}(k, n)}{\partial k}<0 ; \ell=C, m
$$

showing that industry output increases with the number of firms $(n)$ and the fraction of them that are inattentive $(k)$ whereas individual output falls 
w.r.t. both $n$ and $k$. As expected, inattentive firms produce and sell more, as $q^{m}(k, n)>q^{C}(k, n)$ over the whole parameter space.

Substituting (18) and (19) in (4) yields equilibrium profits

$$
\pi^{C}(k, n)=\frac{4 \alpha^{2} \gamma(1+\eta)}{\left[4+2 \eta(n+1)+\eta^{2} k\right]^{2}}
$$

and

$$
\pi^{m}(k, n)=\frac{\alpha^{2} \gamma(2+\eta)^{2}}{\left[4+2 \eta(n+1)+\eta^{2} k\right]^{2}},
$$

which, in turn, reveal that inattentive firms not only supply more output but also earn higher profit. Hence, when neglecting their individual impact on industry output, for any given $n$ and $k$ firms behave more aggressively in terms of output and aggressiveness pays in terms of profit.

\subsection{Stage I}

In the first stage, firms simultaneously decide whether in the second stage they will be attentive or inattentive. In what follows, we use a stability criterion borrowed from coalition theory (d'Aspremont et al., 1983; Donsimoni et al., 1986). Given $n \geq 2$ firms, there exists a subgame perfect equilibrium partition $\{k, n-k\}$ in which $k \geq 1$ inattentive firms coexist with $n-k$ attentive firms if and only if no inattentive firm has a unilateral incentive to become attentive because

$$
\pi^{C}(k-1, n)-\pi^{m}(k, n)<0
$$

and no attentive firm has an incentive to become inattentive because

$$
\pi^{m}(k+1, n)-\pi^{C}(k, n)<0 .
$$

The following result holds:

Lemma 2 Consider an industry in which $n$ firms compete by choosing the output levels of their differentiated products. In making this choice, firms can decide whether or not to take the impact of their individual choices on aggregate output into account. Then, no subgame perfect equilibrium in pure strategies exists in which some firms take the aggregate impact of their individual choices into account while others do not $(0<k<n)$. 
Proof. Consider any given partition $\{k, n-k\}$ with $k \in(0, n)$. Given $(22)$ and (23), condition (24) is satisfied if and only if

$$
k-1>\frac{2(2+\eta) \sqrt{\eta+1}-2 \eta(n-1)}{\eta^{2}},
$$

while condition (25) is satisfied if and only if

$$
0<k<\frac{2(2+\eta) \sqrt{\eta+1}-2 \eta(n-1)}{\eta^{2}} .
$$

Hence, (22) and (23) cannot be satisfied at the same time and for all parameter values either an attentive or an inattentive firm has a unilateral incentive to deviate from $\{k, n-k\}$.

Then, we can prove:

Proposition 3 Consider an industry in which $n$ firms compete by choosing the output levels of their differentiated products. Firms can decide whether or not to take into account the impact of their decision on aggregate output, that is, they can decide whether or not to be attentive. Define $n_{L} \equiv 1+$ $\frac{2}{\eta} \sqrt{\eta+1}$ and $n_{H} \equiv 1+\left(1+\frac{2}{\eta}\right) \sqrt{\eta+1}$. Then, for $1<n<n_{L}$ there exists a unique subgame perfect equilibrium in pure strategies in which all firms are attentive. For $n>n_{H}$ there exists a unique subgame perfect equilibrium in pure strategies in which all firms are inattentive. For $n_{L} \leq n \leq n_{H}$ there are two subgame perfect equilibria in pure strategies, one in which all firms are inattentive and the other in which all firms are attentive.

Proof. Consider first the partition $\{k, n-k\}=\{0, n\}$ in which all firms are attentive. Unilateral deviation from the Cournot-Nash outcome pays if and only if the profit of an inattentive firm as a singleton is larger than any firm's profit when all firms are attentive. Formally, this happens for

$$
\pi^{m}(1, n)-\pi^{C}(0, n)>0
$$

with (22) and (23) implying

$$
\pi^{m}(1, n)-\pi^{C}(0, n)=-\frac{\alpha^{2} \gamma \eta^{2}[4+\eta(8+\eta(4-n(n-2)+\eta))]}{[\eta(n+1)+2]^{2}\left[4+2 \eta(n+1)+\eta^{2}\right]^{2}} .
$$


This expression is positive if and only if its numerator is positive, which is the case for

$$
n-1>\left(1+\frac{2}{\eta}\right) \sqrt{\eta+1}
$$

Consider now the partition $\{n, 0\}$ in which all firms are inattentive. Unilateral deviation from this outcome pays if and only if the profit of an attentive Cournot firm as a singleton is larger than the profit of any firm's profit when all firms are inattentive. The difference between these profits corresponds to

$$
\pi^{C}(n-1, n)-\pi^{m}(n, n)=\frac{\alpha^{2} \gamma \eta^{2}\left[4+\eta\left(4-\eta(n-1)^{2}\right)\right]}{(n \eta+2)^{2}[4+\eta(2-\eta+n(2+\eta))]^{2}} .
$$

This expression is positive if and only if its numerator is positive, which is the case for

$$
0<n-1<\frac{2}{\eta} \sqrt{\eta+1} .
$$

Hence, for $0<n-1<\frac{2}{\eta} \sqrt{\eta+1}$ unilateral deviation from $\{k, n-k\}=\{n, 0\}$ pays whereas unilateral deviation from $\{k, n-k\}=\{0, n\}$ does not, and for $n-1>\left(1+\frac{2}{\eta}\right) \sqrt{\eta+1}$ unilateral deviation from $\{k, n-k\}=\{0, n\}$ pays whereas unilateral deviation from $\{k, n-k\}=\{n, 0\}$ does not. Together with Lemma 2, this implies the results stated in the proposition, if one defines $n_{L} \equiv 1+\frac{2}{\eta} \sqrt{\eta+1}$ and $n_{H} \equiv 1+\left(1+\frac{2}{\eta}\right) \sqrt{\eta+1}$.

The foregoing analysis illustrates that only two equilibrium market structures exist. The first involves the industry-wide adoption of inattention. The second is that where all firms remain attentive.

Figure 2 provides a graphical representation of the parametric conditions supporting the three alternative outcomes described in Proposition 3 with $n \geq 1$ on the vertical axis and $\eta \geq 0$ on the horizontal one. The two curves depict $n_{L}$ and $n_{H}$ as functions of $\eta$ with the former lying below the latter. Curve $n_{L}$ is convex in $\eta$, with $n_{L} \geq 2$ for all $\eta \in(0,2(1+\sqrt{2})]$ and $\lim _{\eta \rightarrow \infty}=1$; curve $n_{H}$ takes a minimum in correspondence of $\eta=$ $1+\sqrt{5}$, at which $n_{H}=4.3302$, and then has an inflection point at $\eta=$ 8.899, at which $n_{H}=4.8534$; moreover, $\lim _{\eta \rightarrow \infty}=\infty$. The two curves, together with the horizontal line at $n=2$, partition the parameter space in three areas. Above $n_{H}$ the unique subgame perfect equilibrium features only inattentive firms. Below the upper envelope of $n_{L}$ and $n=2$, the unique 
subgame perfect equilibrium features only attentive firms (this also implies, intuitively, that a pure monopolist is surely attentive). Between $\max \left\{n_{L}, 2\right\}$ and $n_{H}$ there are two subgame perfect equilibria in which all firms are either inattentive or attentive. Hence, large $n$ and large $\eta$ support monopolistic competition as the unique equilibrium market structure whereas small $n$ and small $\eta$ support oligopoly as the unique equilibrium market structure. For intermediate value of $n$ and $\eta$ both monopolistic competition and oligopoly are equilibrium market structures.

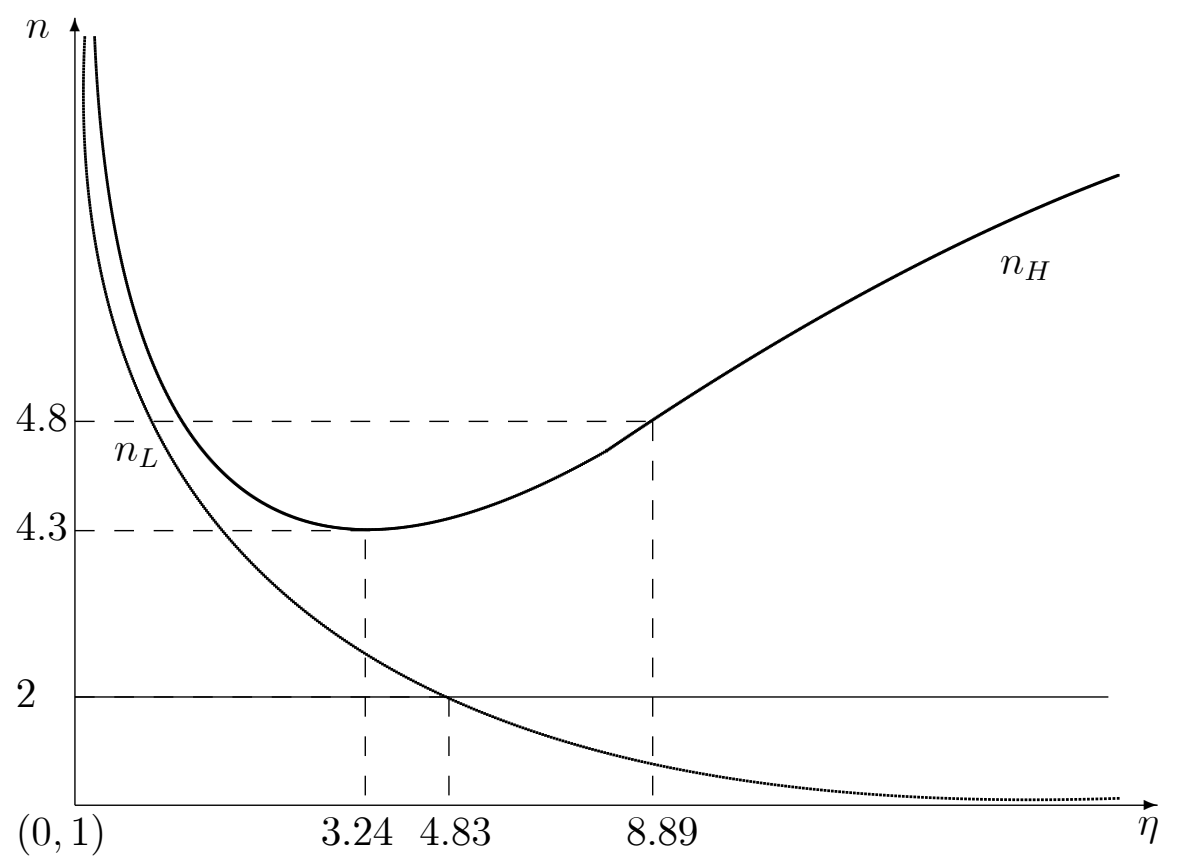

Figure 2 Oligopoly vs monopolistic competition

The figure shows that, for any given degree of aggregate dependence $\eta$, there exists a threshold number of firms above which monopolistic competition is an equilibrium market structure. This number is the closest integer to $n_{L}$ from above and need not be very large except for very small values of $\eta$. For instance, it equals 22 for $\eta=0.1,9$ for $\eta=0.3,6$ for $\eta=0.5$, and 5 for $\eta=0.9$. Moreover, for any given $\eta$, there also exists a threshold number of firms above which monopolistic competition emerges as the unique equilibrium market structure. This number is the closest integer to $n_{H}$ from 
above and need not be very large except for very small or very large values of $\eta$. For instance, it equals 24 for $\eta=0.1,10$ for $\eta=0.3,8$ for $\eta=0.5,5$ for $\eta=0.9$ and does not rise back to 24 until around $\eta=500$. Note that this is very different from saying that in the limit monopolistic competition 'approximates' oligopoly as $n$ goes to infinity. Instead, for $n>n_{H}$ monopolistic competition is 'the' equilibrium outcome rather than its approximation. Note also that the minimum of the $n_{H}$ curve corresponds to $\eta=1+\sqrt{5} \mathrm{im}$ plying $n_{H}=4.3302$ so that $n \geq 5$ is a necessary condition for monopolistic competition to be the unique equilibrium market structure.

In general, the shape of $n_{H}$ can be interpreted in the following terms. As differentiation increases (or, $\eta$ diminishes towards zero), firms become increasingly aware that strategic interaction is disappearing and they are about to become pure monopolists in separate markets. This goes along with $n_{L}$ shooting up (and $n_{H}$ doing the same). Consequently, any finite number of firms will play attentively. Conversely, if differentiation shrinks (or, $\eta$ increases), the upward sloping portion of $n_{H}$ says that the number of firms must increase at an increasing rate in order for inattentive behaviour to be admissible at equilibrium when goods are very close substitutes. That is, for monopolistic competition to be the unique equilibrium, higher fragmentation must act as a substitute for product differentiation.

Of course, Proposition 3 also implies the existence of a mixed strategy equilibrium, as the two fully symmetric industry configurations are subgame

perfect for any $n \in\left[n_{L}, n_{H}\right]$. This entails that the present model explains the emergence of mixed populations of firms as a consequence of randomization in scenarios admitting multiple equilibria in pure strategies.

\section{Conclusion}

We have modeled the endogenous emergence of market structure in an industry where a discrete number of firms compete by choosing the output levels of their differentiated products. In making this choice, they can strategically decide whether or not to consider the impact of their individual decisions on aggregate output. We have labeled these two cases as 'strategic attention' or 'strategic inattention' respectively. The attention and inattention choices are interpreted as if the firm chose between behaving as a Cournot oligopolist or a monopolistically competitive unit.

We have shown that there exist two threshold numbers of firms such 
that: when the number of firms in the industry is below the lower threshold, there is a unique subgame perfect equilibrium in pure strategies in which all firms take the aggregate impact of their individual choices into account as in standard oligopoly; when the number of firms is above the higher threshold, there is a unique subgame perfect equilibrium in pure strategies in which all firms disregard their aggregate impact as in standard monopolistic competition; when the number of firms is between the two thresholds, there are two subgame perfect equilibria in pure strategies, one in which all firms consider their aggregate impact and the other in which they do not. In this last case, a mixed strategy equilibrium also exists, which has its counterpart in the real world where firms of different types coexist in many markets.

We have shown that our model of 'strategic inattention' is isomorphic to a model of 'strategic delegation' of output choices by firm owners to managers in which managerial compensation is based on relative profit performance. In other words, the monopolistic competition behavior can be mimicked through a specific form of delegation. Accordingly, even in the presence of only few firms, 'strategic delegation' can lead to the emergence of monopolistic competition as the equilibrium market structure by de facto implementing 'strategic inattention'. In this respect, one should observe less delegation based on relative profit performance in industries characterized by the presence of few firms, strong product differentiation and marginal cost steeply rising with output.

In terms of comparative statics, we have found that the lower threshold decreases with the relative importance of aggregate output for individual firm profit as dictated by product differentiation and the gradient of marginal cost. In particular, if product differentiation is weak and marginal cost does not increase steeply with output, oligopoly emerges as the unique equilibrium market structure only when the number of firms is very small. The relation between the higher threshold and the relative importance of aggregate output is, instead, U-shaped.

Three final comments are in order. First, with fully symmetric demand and cost functions, equilibrium outcomes with a mixed population of firms (some considering and others neglecting their respective impacts on aggregate output) exists only in mixed strategies. These 'mixed' outcomes may be quite relevant in practice and would be easy to generate with pure strategies if one allowed for firms' heterogeneity and 'rational inattention' motivated by costly information acquisition and processing. Investigating whether this would also be possible with 'strategic inattention' in the absence of any cost 
of acquiring and processing information is an interesting direction of future research. Second, we have considered 'strategic inattention' and 'strategic delegation' with relative performance evaluation in the case of single-product firms. It may be interesting to extend the analysis to the case of multiproduct firms that can choose whether to neglect the individual impact of a product output on firm or industry total output. This direction of investigation may have some relation with the literature on firm divisionalization (e.g., Kokovin et al., 2014). Third, our analysis has been based on a static model. A dynamic approach could be adopted to investigate the intertemporal dimension of strategic inattention, possibly resorting to differential game models with their various solution concepts related to different assumptions about information availability and use. 


\section{References}

[1] Aggarwal, R., and A. Samwick (1999), "Executive compensation, strategic competition, and relative performance evaluation: Theory and evidence", Journal of Finance, 54, 1999-2043.

[2] Anderson S., N. Erkal and D. Piccinin (2013), "Aggregative oligopoly games with entry", CEPR Discussion paper 9511.

[3] Barro, J.R., and R.J. Barro (1990), "Pay, Performance, and Turnover of Bank CEOs", Journal of Labor Economics, 8, 448-481.

[4] Barros F. (1997) "Asymmetric information as commitment in oligopoly", European Economic Review, 41, 207-225.

[5] Bassan, B. and M. Scarsini (1995), "On the value of information in multi-agent decision theory", Journal of Mathematical Economics, 24, $557-576$.

[6] Bassan, B., M. Scarsini and S. Zamir (1997), "I don't want to know! Can it be rational?", Discussion paper no. 158, Center for Rationality and Interactive Decision Theory, The Hebrew University of Jerusalem.

[7] Bassan, B., O. Gossner, M. Scarsini and S. Zamir (2003), "Positive value of information in games", International Journal of Game Theory, 32, 17-31.

[8] Behrens, K. and Y. Murata (2007), "General equilibrium models of monopolistic competition: a new approach", Journal of Economic Theory, 136, $776-787$.

[9] Bernheim, B.D. and M.D. Whinston (1985), "Common marketing agency as a device for facilitating collusion", RAND Journal of Economics, 16, 269-281.

[10] Bernheim, B.D. and M.D. Whinston (1986), "Common agency", Econometrica, 54, 923-942.

[11] Bowley, A.L. (1924), The mathematical groundwork of economics, Oxford, Oxford University Press. 
[12] Chirco, A., C. Colombo and M. Scrimitore (2013), "Quantity competition, endogenous motives and behavioral heterogeneity", Theory and Decisions, 74, 55-74.

[13] d'Aspremont, C. and R. Dos Santos Ferreira (2010), "Oligopolistic competition as a common agency game", Games and Economic Behavior, 70, 21-33.

[14] d'Aspremont, C., R. Dos Santos Ferreira and L.-A. Gerard-Varet (1996), "On the Dixit-Stiglitz model of monopolistic competition", American Economic Review, 86, 623-629.

[15] d'Aspremont, C., A. Jacquemin, J.J. Gabszewicz and J. Weymark (1983), "On the stability of collusive price leadership", Canadian Journal of Economics, 16, 17-25.

[16] Dixit, A.K. (1979), "A model of duopoly suggesting the theory of entry barriers", Bell Journal of Economics, 10, 20-32.

[17] Donsimoni, M.-P., N.S. Economides and H.M. Polemarchakis (1986), "Stable cartels", International Economic Review, 27, 317-327.

[18] Dunne, T., S. D. Klimek, M. J. Roberts and D. Yi Xu (2013), "Entry, exit, and the determinants of market structure", RAND Journal of Economics, 44, 462-487.

[19] Etro, F. (2008), "Stackelberg competition with endogenous entry", Economic Journal, 118, 1670-1697.

[20] Etro, F. (2011), "Endogenous market structures and contract theory: Delegation, principal-agent contracts, screening, franchising and tying", European Economic Review, 55, 463-479.

[21] Fershtman, C. and K. Judd (1987), "Equilibrium incentives in oligopoly", American Economic Review, 77, 927-940.

[22] Fershtman, C., K. Judd and E. Kalai (1991), "Observable Contracts: Strategic Delegation and Cooperation", International Economic Review, 32, 551-559. 
[23] Gibbons, R., and K. Murphy (1990), "Relative performance evaluation for chief executive officers", Industrial \& Labor Relations Review, 43, 30S-51S.

[24] Janakiraman, S., R. Lambert and D. Larcker (1992), "An Empirical Investigation of the Relative Performance Evaluation Hypothesis", Journal of Accounting Research, 30, 53-69.

[25] Jansen, T., A. van Lier and A. van Witteloostuijn (2007), "A note on strategic delegation: The market share case", International Journal of Industrial Organization, 25, 531-539.

[26] Jansen, T., A. van Lier and A. van Witteloostuijn (2009), "On the impact of managerial bonus systems on firm profit and market competition: The cases of pure profit, sales, market share and relative profits compared", Managerial and Decision Economics, 30, 141-153.

[27] Joh, S. (1999), "Strategic Managerial Incentive Compensation in Japan: Relative Performance Evaluation and Product Market Collusion", Review of Economics and Statistics, 81, 303-313.

[28] Kadane, J.B., M.J. Shervish and T. Seidenfel (1996), "Reasoning to a forgone conclusion", Journal of the American Statistical Association, 91, 1228-1235.

[29] Keen, S. and R. Standish (2006), "Profit maximization, industry structure, and competition: A critique of neoclassical theory", Physica A, 370, 81-85.

[30] Kamien, M.I., Y. Tauman and S. Zamir (1990), "On the value of information in a strategic conflict", Games and Economic Behavior, 2, 129-153.

[31] Kokovin, S., M. Parenti, J.-F. Thisse and E. Zhelobodko (2014), "Markets with dominant firms and competitive fringes", CORE, mimeo.

[32] Lambertini, L. (2017), An Economic Theory of Managerial Firms: Strategic Delegation in Oligopoly, London, Routledge.

[33] Melitz, M. and G.I.P. Ottaviano (2008), "Market size, trade, and productivity", Review of Economic Studies, 75, 295-316. 
[34] Miller, N.H. and A.I. Pazgal (2001), "The equivalence of price and quantity competition with delegation", RAND Journal of Economics, 32, 284-301.

[35] Murphy, K. (1999), "Executive compensation", Handbook of Labor Economics, 3, Amsterdam, Elsevier, 2485-2563.

[36] Ottaviano, G.I.P., T. Tabuchi and J.F. Thisse (2002), "Agglomeration and trade revisited", International Economic Review, 43, 409-436.

[37] Parenti, M. (2018), "Large and small firms in a global market: David vs. Goliath", Journal of International Economics, 110, 103-118.

[38] Ritz, R.A. (2008), "Strategic incentives for market share", International Journal of Industrial Organization, 26, 586-597.

[39] Safra, Z. and Sulganik E. (1993), "The value of information with general preference relations", Working paper 34-93 Tel Aviv University, Faculty of Management.

[40] Salas Fumas, V. (1992), "Relative performance evaluation of management: The effects on industrial competition and risk sharing", International Journal of Industrial Organization, 10, 473-489.

[41] Shimomura, K.-I. and J.F. Thisse (2012), "Competition among the big and the small", RAND Journal of Economics, 43, 329-347.

[42] Singh, N., and X. Vives (1984), "Price and quantity competition in a differentiated duopoly", RAND Journal of Economics, 15, 546-554.

[43] Sims, C.A. (1998), "Stickiness", Carnegie-Rochester Conference Series on Public Policy, 49, 317-356.

[44] Sims, C.A. (2003), "Implications of rational inattention", Journal of Monetary Economics, 50, 665-690.

[45] Sims, C. A. (2010), "Rational inattention and monetary economics", Handbook of Monetary Economics, 3, 155-181.

[46] Sklivas, S. (1987), "The strategic choice of management incentives", RAND Journal of Economics, 18, 452-458. 
[47] Spence, A.M. (1976), "Product differentiation and welfare", American Economic Review, 66, 407-414.

[48] Vickers, J. (1985), "Delegation and the theory of the firm", Economic Journal (Conference Supplement), 95, 138-1 47.

[49] Wiederholt, M. (2010), "Rational inattention" , in: S. Durlauf and L. E. Blume (Eds.), The New Palgrave Dictionary of Economics, online edition: http://www.palgraveconnect.com 